\title{
O ACONTECIMENTO EM MEIO AO EXERCíCIO DA PRÁTICA PEDAGÓGICA
}

\section{THE EVENT IN THE MIDDLE OF THE PEDAGOGICAL PRACTICE EXERCISE}

\author{
Daniervelin Renata Marques Pereira ${ }^{1}$ \\ USP - Universidade de São Paulo
}

\begin{abstract}
RESUMO: Diante de alguns enunciados inseridos em práticas pedagógicas, é inevitável acionar concepções desse exercício ligadas à rotina e à programação. Em meio à regularidade ou tradição nessas práticas, elevam-se, entretanto, cenas de maior intensidade, vistas como acontecimento, que desencadeiam outras em que imperam as necessárias estratégias de ajustamentos. O que nos conduz ainda à abordagem que aqui apresentamos é a convergência que observamos entre a teorização dessas noções de programação e desvio no campo pedagógico e o direcionamento mais recente da semiótica para uma teorização do aspecto contínuo e sensível dos eventos. Para a análise feita, selecionamos enunciados de um curso realizado em ambiente digital, pelo qual demonstramos essa convergência teórica e, ao mesmo tempo, servimo-nos deles para encontrar ocorrências que validam esse ponto de vista.
\end{abstract}

PALAVRAS-CHAVE: acontecimento; discurso pedagógico; semiótica tensiva.

\begin{abstract}
Before some statements embedded in pedagogical practices, it is unavoidable to activate concepts of this exercise, related to routine and schedule. Amidst the regularity or tradition in these practices, however, the most intense scenes rise, seen as events that make others emerge, in which the necessity of adjustment strategies dominates. What leads us still to this approach here presented is the convergence between the theory of these notions of programming and deviation in the educational field and the latest semiotic studies direction, to a sensitive and continuous theorization of the events aspect. For the analysis accomplished, we selected the statements from a course held in the digital environment, in order to demonstrate this theoretical convergence and, at the same time, use them to find instances that validate this view.
\end{abstract}

KEYWORDS: event; pedagogical discourse; tensive semiotics.

\section{Introdução}

O discurso pedagógico ou didático é conhecido como o lugar onde se constroem e circulam os saberes. Esses podem ser mais ou menos fechados de acordo com seu estatuto dentro do conjunto de valores acordados entre enunciador e enunciatário.

Fontanille (1983) se dedicou à reflexão sobre a transformação de um universo de saberes de algum campo em doxa. Segundo ele, esse campo de saberes fechados se

\footnotetext{
${ }^{1}$ Doutoranda em Semiótica e Linguística Geral pela Universidade de São Paulo, <daniervelin@gmail.com>.
} 
caracteriza pela terminatividade, pela busca alcançada, pela modalização do dever ser e pela predominância do papel de destinatário assumido pelo aluno. Em relação oposta a esse polo, estão os contravalores ligados às formas polêmicas e, às vezes, tomados como "erro", que distanciam o sujeito daquela "verdade", a "ortodoxia", como afirma Fontanille (1983, p. 37).

Interessa-nos, aqui, essa relação entre um conjunto de saberes dados como consensuais, sedimentados, a serem transmitidos por estratégias de manipulação previamente estipuladas e, de outro lado, a aquisição desses saberes e de outros relevantes ao sujeito, por estratégias de ajustamento que levem em conta questões complexas, como as necessidades cognitivas de cada sujeito, estilos de aprendizagem, modos de introdução dos temas na aula e outras que abandonam as formas habituais e instauram a tensão entre o dado e o novo. O que está em jogo aí é, de um lado, os objetos buscados e, de outro, os percursos que levam a eles, conformes ou não aos valores euforizados para o ensino, como perfil dos alunos, tema estudado, entre outros conhecidos como "contexto educativo" ou "contexto de inserção" (CORRÊA, 2007).

Mais do que a simples busca por novidade, alguns professores e alunos encontram no ambiente digital um espaço em que os deslocamentos resultantes dessa tensão entre o dado e o novo e manifestados tanto na abordagem do tema quanto na organização do espaço significam um esforço de ressignificar o que se tornou banalizado, os percursos do ensino-aprendizagem.

Motivados por essas questões, seguimos em busca de sentidos apoiados em alguns conceitos da semiótica greimasiana em seus desdobramentos tensivos.

\section{Um desvio pela área verde}

Foi durante uma aula sobre games em educação ${ }^{2}$ num chat educacional (batepapo em plataforma digital), que nos deparamos com um esquema para abordar uma relação entre o esperado e o inesperado no universo das práticas educativas.

O problema começa com a observação de que a oposição simples de termos e a escolha de apenas um nem sempre é profícua para designar práticas que existem na/pela tensão entre os conceitos. Quando falamos em instrução e aprendizado, o mais comum é a crença de que o que está por trás dessa relação é uma implicação (se x, então y) e não uma concessão (embora x, y). Essa aparente estabilidade da relação implicativa, ao ser posta em xeque durante a aula mencionada, causou certa surpresa e curiosidade também associadas à forma como a discussão foi conduzida.

O professor apresentou inicialmente um esquema (Figura 1) por meio de um link e iniciou a discussão sobre as concepções de educação, instrução, treinamento, ensino e aprendizagem e inferências possíveis da relação entre elas. Smith e Ragan (2005), citados por ele, definem instrução como um tipo de educação e treinamento, por sua vez, como um tipo de instrução. Todas as experiências que envolvem algum tipo de aprendizagem seriam educação, inclusive o aprendizado não planejado, casual e informal; enquanto a instrução abarcaria intenção na produção do aprendizado. O treinamento, por sua vez, estaria ligado a habilidades muito específicas que precisassem ser aplicadas de imediato (por exemplo, treinamento para uso de uma máquina). Os autores definem o ensino como experiências que são facilitadas por um ser humano, excluindo daí as ferramentas, como o computador, o CD

\footnotetext{
2 "Games em educação no Second Life" foi um curso a distância acompanhado de 03/2010 a 06/2010 para nossa pesquisa de doutorado. Ele teve como cenário um "mundo virtual" em três dimensões (3D) que era formado, principalmente, por um chat educacional escrito e a "teatralização" de um encontro presencial por meio dos avatares (figuras de pessoas).
} 
etc. Enfim, cada um dos quatro conceitos poderiam ser representados por um grupo dentro do outro, como esquematizado na Figura 1:

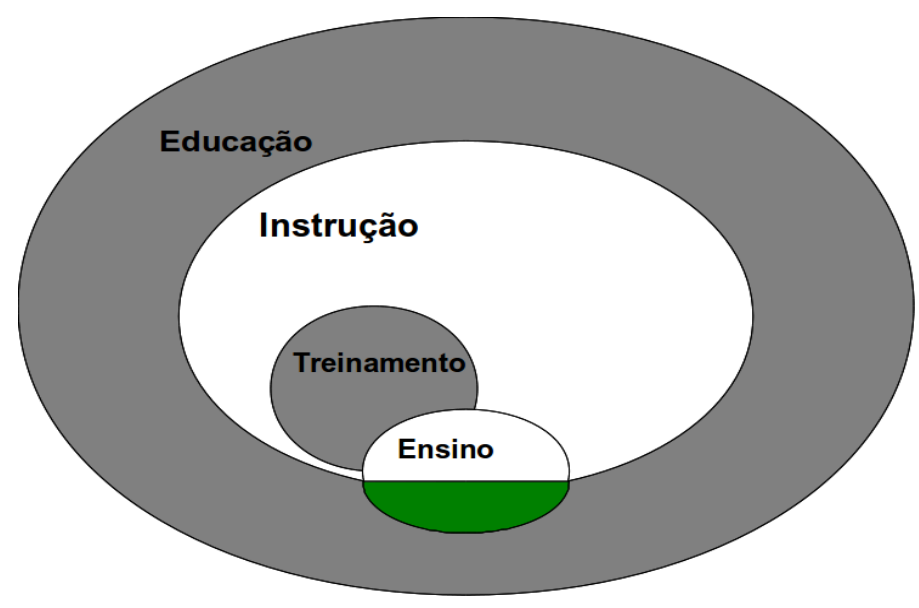

Figura 1: Esquema apresentado por Lindeman (2005) e ajustado por Mattar (2010).

A área verde destacada nessa figura - e não prevista entre os termos mais comuns citados no discurso pedagógico - foi a grande novidade, porque foi destacada numa segunda imagem, depois de ser apresentado o esquema apenas com os quatro conceitos. $\mathrm{O}$ professor pediu para os alunos tentarem sugerir que valores estariam reservados para esse lugar. Com maior ou menor grau de especificidade e abstração, mas bem estimulados, os alunos foram respondendo e se complementando no diálogo pelo chat. Retomando a voz, o professor disse que a área verde remetia, então, a circunstâncias em que o aprendizado se deu pela mediação do professor, mas sem terem sido rigidamente antecipadas no programa de ensino, ou seja, houve educação, mas sem instrução. Sua especificidade em relação à grande área da Educação é a presença de um guia. No discurso pedagógico abaixo, podemos perceber uma tentativa de apreender tal fenômeno de forma mais figurativa, feita por um estudioso também citado durante a aula pelo professor:

É nessa área verde que podemos enxergar a figura do professor atuando como um guia e um facilitador, de que tanto fala a literatura. É nessa área verde que conseguimos imaginar o respeito aos diferentes estilos de aprendizagem dos alunos. É nessa área que se reconhece que os alunos, que hoje têm acesso à Internet, chegam até nós, professores, com níveis de conhecimento sobre os assuntos e interesses muito desnivelados, e então objetivos de aprendizagem fixos podem não fazer sentido para eles. (MATTAR, 2010, s/p).

É nessa área, complementando Mattar, que se dá o aprendizado de uma forma dinâmica, sensível e subjetiva (porque pressupõe a presença especial dos sujeitos e objetos). Esse discurso pedagógico nos interessa por levantar situações que mantêm como pano de fundo um dizer valorizado, mas pouco realizado, justamente pela dependência da força dos contratos assumidos e, com isso, do impulso na busca dos objetos euforizados, que possam "fazer sentido para eles". Quando os destinatários são manipulados para mirar um objeto revestido de valores já desejados, mas até o momento não perceptíveis, dá-se o ensino- 
aprendizagem de forma eficaz, como uma descoberta de interesse mútuo. E é graças ao destinador que esse encontro do sujeito com o objeto, previsto pelo primeiro, é possível. $\mathrm{O}$ que explica, então, a eficácia do que ocorre na "área verde" em relação às outras é o modo de presença desse objeto para o sujeito. Ele surge como surpreendentemente adequado à capacidade de apreensão do sujeito, embora não fosse programado daquele modo. Dessa forma, o sujeito se apresenta ativamente frente ao objeto desejado no momento em que, por uma participação especial (tônica) e orientada, ele o adquire. Esse percurso, portanto, não pode ser dado de antemão, mas construído interativamente entre destinador e sujeito, de forma a garantir a sequência de competências e performances que se alteram continuamente.

Em breve, entretanto, o primeiro objeto que justifica essa sequência - no caso, um dado conhecimento - torna-se parte de uma estrutura mais complexa que precisa ser complementada, permanecendo na memória - ou não, a depender da intensidade da ocorrência - a ocasião em que surgiu como favorável ao aprendizado, potencializando, assim, novos encontros.

Observamos, aqui, uma orientação para a abertura do campo de possibilidades de ensino-aprendizagem. Espera-se que o sobrevir de questões em aula aproxime os sujeitos de experiências mais significativas, na medida em que elas deixam expostas reais necessidades dos sujeitos e não as ideais que o devir pressupõe.

\section{2. $O$ curso do qual se fala}

Além de despertar em nós reflexões teóricas, o curso considerado pode também ser visto como objeto em que as questões problematizadas aqui estão presentes.

Frequentemente, costumamos receber, principalmente da mídia, concepções da educação mediada pelas novas tecnologias como algo extremamente inovador, porque se distanciam do tradicional ensino em salas de aula físicas, com seus habituais artefatos, mas também predomina uma concepção de transposição de métodos e técnicas com simples migração para novo espaço. Entretanto, o que raramente é posto em discussão explicitamente são as estratégias que envolvem essa distância e aproximação entre práticas e, sobretudo, em que medida as tecnologias propiciam uma ruptura com a pesada carga de fórmulas inquestionáveis de se alcançar o saber.

Alguns cursos a distância, como o que vamos apresentar em alguns trechos, jogam com o digital e o presencial de forma bastante lúdica e diversa do que é feito nas práticas pedagógicas habituais, sejam presenciais ou mesmo as digitais em sua forma modelo. Observamos a sobreposição, em alguns momentos, de práticas e mesmo a sua fusão, o que pode sensibilizar de diferentes formas os sujeitos.

O curso de que tratamos é o "Games em educação no Second Life" que, como anuncia o título, aconteceu no Second Life, um mundo digital de formato tridimensional para "simulação da vida". ${ }^{3}$ O ambiente é composto por objetos diversos construídos para situar os sujeitos-participantes, inclusive os avatares ou atores, cuja aparência é mutável. No espaço do curso, "Ilha da educação", havia painéis com anúncios de eventos e um local para teletransporte (transferência) a outros espaços, o que podia ser feito também por uma ferramenta de busca presente entre as opções do ambiente. O diálogo, nesse mundo, prevê

\footnotetext{
${ }^{3}$ De acordo com definição do site de downloads: "O Second Life é um simulador da vida real, em um mundo virtual totalmente $3 \mathrm{D}$, onde os limites de interação com o game vão além da sua criatividade. Nele, além de interagir com jogadores de todo o mundo em tempo real, é possível também criar seus próprios objetos, negócios e até mesmo personalizar completamente seu avatar, tudo em modelagem 3D". Disponível em: <http://www.baixaki.com.br/download/second-life.htm>. Acesso em: 12 de outubro de 2010.
}

Disponível em: http://seer.fclar.unesp.br/casa 
mais traços híbridos do presencial: voz e gestos, além da escrita. $\mathrm{O}$ chat, gênero que nos interessa bastante neste estudo, era o principal determinante das posições actanciais e actoriais assumidas e representadas na cena visual.

Pela Figura 2, podemos perceber a "teatralização" de um encontro entre os sujeitos e as estratégias figurativas de aproximação e afastamento entre as práticas presencial/online:

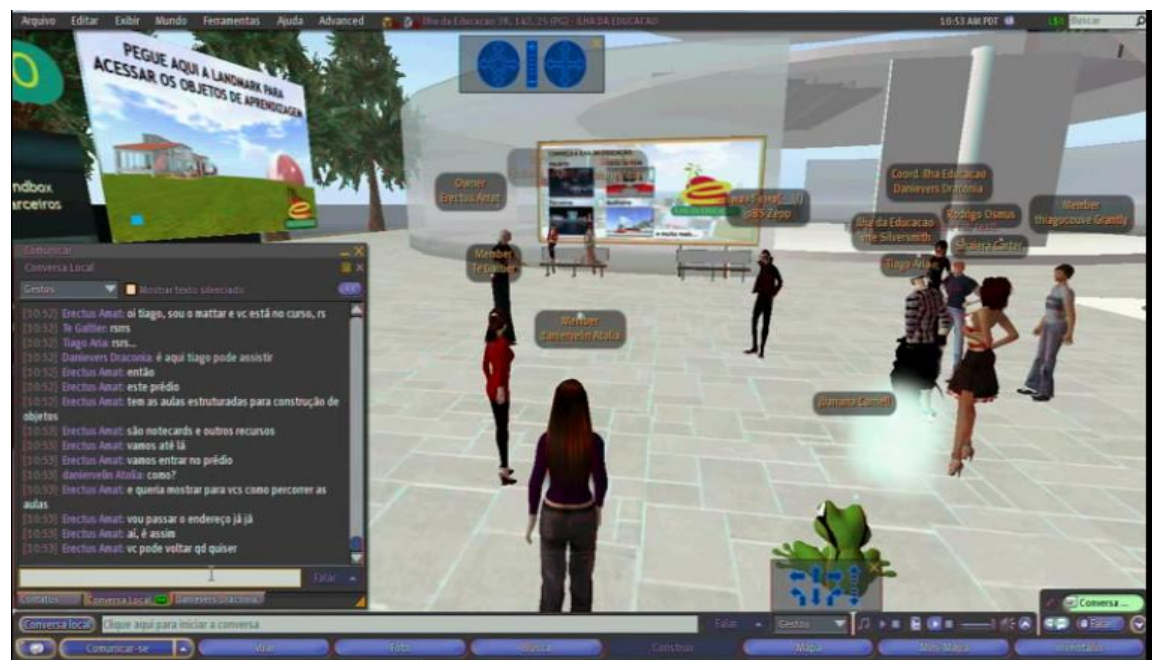

Figura 2: Cena do curso "Games em educação no Second Life"

Como um fenômeno fora do espaço tradicional das práticas educativas, o ensino em ambiente digital já se apresenta como diferentemente marcado pela interferência do tempo, espaço e aspecto que implicam uma nova organização da concepção de prática pedagógica (MATTE; PEREIRA, 2010). A posição dos sujeitos em chat, como espaço da comunicação verbal, tende a ser mais livre do que em sala de aula física, o que é observado pela sequência de turnos que se intercalam. ${ }^{4}$ Essa organização também se deve ao contrato firmado no início desse curso: de colaboração, participação livre, construção coletiva, o que diminui a rigidez da separação destinador/destinatário em sala de aula, como podemos ver nesse trecho da primeira aula do curso a seguir.

(...)

[15:01] Professor: como eu disse: no fundo estou considerando que vamos construir juntos

[15:01] Professor: tanto conceitos (e vamos discordar no processo, é claro)

(...)

[15:01] Professor: quanto materiais como sugestões de pesquisas, uma compilação de games edu etc.

(...) (Interação do dia 31/03/2010 - primeira aula do curso "Games em educação no Second Life").

\footnotetext{
${ }^{4}$ Como próprio da composição dos chats, os turnos não se apresentam ordenadamente, mas por fragmentos entrecortados que vão sendo articulados logicamente pelos destinatários, já que os sujeitos são relativamente livres para se manifestar quando querem e as falas são cortadas para atender às necessidades de fluxo do meio. É por isso que nas citações presentes aqui, entre enunciados de continuidade, intercalam-se outros numa sequência um tanto confusa inicialmente. Vale lembrar, então, que a organização formal foi mantida tal como produzida no original: horário da intervenção, nome fictício do interlocutor e enunciado.
}

Disponível em: http://seer.fclar.unesp.br/casa 
O espaço de interação entre as figuras dos atores na cena visual é o que destaca essa prática como híbrida, reunindo elementos do presencial e digital de forma lúdica, mas com objetivos educativos claros. Esse cenário é significativo ainda na abertura de possibilidades de realização que só um mundo imaginário permite, mas concretizado figurativamente: metamorfose do corpo para múltiplas formas; construção de percursos espaciais historicamente valorizados, como a viagem que Darwin fez até as ilhas Galápagos, visita a Esparta, a diversos museus, por exemplo. Esse leque de opções apresentadas pelo ambiente prepara, de alguma forma, o sujeito para experiências variadas e, quase sempre, inesperadas em que os objetos desejados parecem estar mais acessíveis. A seguir, temos um exemplo da surpresa causada pelas possibilidades do mundo digital:

$(\ldots)$

[15:19] Professor: minha sugestão seguinte era a gente faer a viagem que o Darwin fez

[15:19] Professor: no Bealge

[15:19] Professor: Beagle

[15:19] Professor: nas ilhas Galapagos

[15:19] Aluna 1: ta brincando, posso?

(...) (Interação do dia 05/05/2010 - curso "Games em educação no Second Life").

\section{Acontecimento}

Com base nos estudos de Merleau-Ponty sobre Fenomenologia, filtrados por Greimas (2002) na abordagem do impacto que a experiência estética provoca e, também, por outros estudiosos, Fontanille e Zilberberg (2001) e Tati (2010), por exemplo, que se dedicaram ao desdobramento dessa noção, sabemos que a noção de acontecimento não precisa necessariamente ser estética, mas pode referir-se a qualquer situação que irrompe o campo de presença fundando a percepção sensível, relativa ao encontro do homem com o mundo (DISCINI, 2010). Está, portanto, associada a uma quebra, mesmo que momentânea, de uma dada rotina historicamente construída. No caso específico do discurso pedagógico, o objetivo mais geral é fazer saber. Entretanto é o processo até sua realização que é posto aqui em questão: se de acordo com métodos e técnicas tradicionais, que incidem com maior ou menor força no programa de cada aula, ou inesperadamente, acolhendo elementos externos que sinalizam novas necessidades de outros objetos que, embora imprevistos, convergem para o objetivo desejado.

Nos dois trechos abaixo, de duas aulas subsequentes, dia 14/04/2010 e 28/04/2010, do curso anteriormente citado, acontecem duas situações que merecem destaque: 1) um tópico desvia a discussão para novas questões inesperadas dentro do quadro teórico proposto e leva os sujeitos a um conflito e 2) a discussão se intensifica mais do que o esperado e leva à mudança de planos.

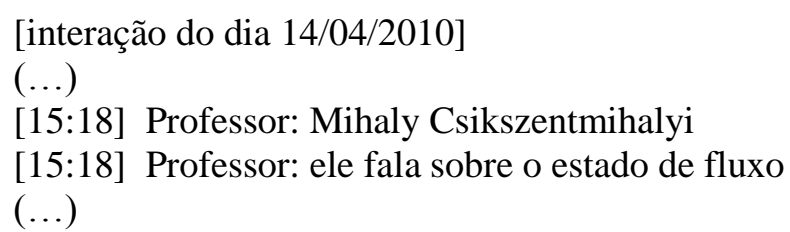

[15:23] Professor: No estado de fluxo, há harmonia na consciência, o que ocorre quando a energia psíquica - ou atenção - é investida em objetivos Disponível em: http://seer.fclar.unesp.br/casa 
realistas, e quando nossas habilidades estão em um nível equivalente ao das oportunidades para a ação.

[15:23] Professor: Nesses momentos de estado de fluxo, crescemos e nos tornamos seres mais complexos.

[15:24] Aluna 1: tem a ver com a zona de desenvolvimento proximal, ne?

[15:24] Professor: $O$ oposto da experiência ótima, que pressupõe concentração, seria a entropia ou desordem psíquica.

[15:24] Aluna 4: caramba nem sabia que existia este termo

[15:24] Aluno 2: hmm... legal

[15:24] Professor: vygostky

[15:24] Professor: a diferença entre o que eu faço sozinho e o que faço com o suporte do outro

[15:24] Aluna 1: essa ideia de vc está num nível de desenvolvimento, aprendizagem

[15:25] Professor: mas tem a ideia do suporte

[15:25] Aluna 7: não acho

[15:25] Professor: não acha o que? rs

[15:25] Aluna 4: estou perdida no assunto desculpem...

[15:25] Professor: vamos definir zdp

[15:26] Aluna 4: heheheheh

[15:26] Aluno 2: na ideia do fluxo a experiência individual é que é o foco né?.. ZDP parece que esteja mais a ver com um potencial

[15:26] Professor: Aluna 1, se vc quis dizer p.ex.

[15:26] Professor: que em desenvolvimento, estmaos em fluxo

[15:26] Professor: aí acho que é uma relação interessante

[15:27] Aluna 1: pensei nisso qd vc comentou q no jogo tem algumas questões como dificuldades no nível em q vc está

[15:27] Aluna 7: sim mas as vezes os games nos colocam fora dessa zona, mas sao tao envolventes que prosseguimos jogando

[15:27] Aluna 1: nao pode ser difícil demais, mas tbm nao muito fácil

(..)

[15:32] Professor: aí entra o professor

[15:32] Professor: nessa fase pós-fluxo

[15:32] Professor: só dando o game nas mãos do aluno não resolve

[15:33] Professor: e aí, temos a zdp, o games sozinhos não consegue muitas vezes realizar a reflexão

(...).

[interação do dia 28/04/2010]

(...)

[14:11] Professor: daqui a pouco, vamos para a área brasil

[14:11] Professor: programei uma aula diferente das anteriores

[14:11] Professor: em geral, nas anteriores, eu segui o fluxo dos capítulos do livro

[14:11] Professor: quem está lendo deve ter percebido

[14:11] Professor: em alguns casos, acrescentei coisas, links, etc. que não tinham no livro

[14:12] Professor: mas segui a ordem dos capítulos

(...)

[14:15] Professor: não vou seguir a ordem do livro

[14:15] Professor: mas vou propor alguns temas para a gente debater

[14:15] Professor: na aula passada, no final, acho que conseguimos pela primeira vez uma colaboração muito interesantes

Disponível em: http://seer.fclar.unesp.br/casa 
[14:16] Professor: com a questão do senso crítico e do fluxo

[14:16] Professor: então, queria ver se a gente consegue reproduzir isso hoje

[14:16] Professor: com outro tema

[14:16] Professor: então, vou introduzir o tema geral

[14:16] Professor: e conforme a conversa andar, introduzo outros conceitos do cap., mas sem seguir a ordem

(...)

[16:06] Professor: ]eu tinha planejado, como nas últimas aulas

[16:06] Professor: uma atividade em outra ilha on second life

[16:07] Professor: mas ficmaos poraqui mais do que eu imaginava

[16:07] Professor: desculpem, fazemos isso na próxima aula

(...)

No primeiro trecho, o professor aborda o tema do fluxo na experiência humana, o que ele relaciona ao próprio tema do curso: uso de games em educação. A discussão provoca uma associação feita por uma aluna que os outros sujeitos em comunicação não haviam feito entre: estado de fluxo e Zona de Desenvolvimento Proximal. ${ }^{5}$ Essa interferência na aula causa um certo desconforto, entre discordâncias e incompreensão, ao mesmo tempo em que desperta um interesse singular em torno do assunto. O professor responde com uma tentativa de definição, ou seja, uma parada da parada para domínio da situação perturbadora que se instaurou. A importância dessa fratura na estrutura do curso pode ser notada no momento final do curso quando o professor reelabora a reflexão inicial introduzindo o novo elemento anunciado, dando a ele um valor positivo dentro do quadro teórico em discussão. Segundo Zilberberg (2009, p. 381), "o acontecimento no plano do conteúdo tem por plano da expressão a surpresa e por manifestante discursiva preferencial a exclamação [...]". [tradução nossa, grifo no original]. Acreditamos que os enunciados entre professor e alunos realizam de forma adequada ao evento acadêmico esse acontecimento.

No segundo trecho, referente à aula em que ocorreu a reflexão sobre o esquema que relaciona educação, instrução, treinamento, ensino e a área verde, podemos notar, no início, a posição do professor como aquele que espera um novo acontecimento baseado no ocorrido na aula anterior. De certa forma, ele obteve um efeito bem próximo do experienciado lá, porque a "área verde" e a quebra estabelecida na relação implicativa entre instrução e aprendizado causaram surpresa em todos. Entretanto algo mudou: a preparação dos sujeitos para o que surge no cenário do acontecimento. Como lembra Tatit (2010, p. 54), o sujeito já é preparado pelo destinador para ver e sentir o fenômeno como acontecimento, ou seja, há já algo de esperado no inesperado. Na primeira aula citada, a associação é totalmente inesperada (fratura), enquanto na segunda, pode-se falar de uma escapatória (GREIMAS, 2002), ou seja, uma busca de "ressemantização do cotidiano, [...] de reprogramá-lo no sentido de favorecer nosso contato com os acontecimentos estéticos" (TATIT, 2010, 51), tais como os que ocorrem na fratura. O resultado é a perda do controle temporal, o que se revela quando o professor diz: "ficmaos poraqui mais do que eu imaginava". Ele foi, aqui também, tomado pelo fenômeno, sem conseguir interromper o fluxo da aula para obedecer a uma programação.

\footnotetext{
${ }^{5}$ Zona de Desenvolvimento Proximal (ZDP) é um conceito elaborado por Vygotsky e define a distância entre o nível de desenvolvimento real, determinado pela capacidade de resolver um problema sem ajuda, e o nível de desenvolvimento potencial, determinado através de resolução de um problema sob a orientação de um adulto ou em colaboração com outro companheiro. Quer dizer, é a série de informações que a pessoa tem a potencialidade de aprender, mas ainda não completou o processo, conhecimentos fora de seu alcance atual, mas potencialmente atingíveis.

${ }^{6}$ Frase exata: "ficamos por aqui mais do que eu imaginava", sem o problema de digitação típico da comunicação no gênero chat.
} 
Percebemos, então, que, após o surgimento de um elemento conhecido por alguns, apesar de não ativado na apresentação do conteúdo (previsto), os sujeitos se dedicam à organização da cena enunciativa como estratégia de ajustamento, e o professor, como destinador, desempenha um papel fundamental ao acolher o tópico lançado, dar continuidade à discussão e, assim, permitir a assimilação do acontecimento.

Nas aulas, o destinador instaurado na comunicação, o professor, encadeia uma sequência de informações que fazem parte de um programa maior determinante dos saberes válidos e das associações que entre eles são possíveis. Seu papel de destinador aí é garantido pelo domínio de um conjunto de saberes que é buscado pelos outros sujeitos já previamente manipulados por um querer saber. Esse controle superior pode ser, muitas vezes, da escola, quando define o que os alunos precisam aprender para serem bem-sucedidos. Acreditamos que, ao lado dessa entidade responsável pelo universo de saberes "fechados", estão os valores de uma educação "aberta", tensão que explica o súbito aparecimento de associações, mas que não negam os conhecimentos tomados como válidos.

Os sujeitos "escolares" (professor/aluno) desejam novas associações que levem a formulações cognitivas mais complexas e mesmo a novas formas de tirar proveito delas na prática diária. Eles sabem que novas conexões são possíveis se forem coerentes aos valores euforizados, e elas só fazem sentido se estiverem de acordo com a constituição identitária do sujeito para transformá-lo. Dessa forma, essas associações, visto que nenhum saber nasce do zero, são projetadas como desafio e euforizadas pelo destinador, responsável pela progressão, continuidade narrativa (TATIT, 2010, p. 24). Isso explica por que o professor simplesmente não rejeita a interferência da aluna, mas a coloca em discussão, incitando uma reflexão que pode significar avanço nos estudos sobre o tema e, assim, o aparecimento de sujeitos mais complexos.

\section{Novas formas de presença}

Como vimos até agora, a discussão verbal tida entre os sujeitos e a forma de sua condução explicam "acontecimentos" no que diz respeito ao universo de saberes teóricos como objetos perseguidos pelos sujeitos, sejam descritivos (também chamados de finais) ou modais (valores de fluxo, para aquisição de outros). A tecnologia 3D (3 dimensões), nos trechos citados até agora, teve pouca presença além de mediadora e acessória dessa comunicação verbal entre os sujeitos.

Contudo as figuras que criam um mundo digital de aproximações e afastamentos do mundo natural, em outros momentos, roubam toda a cena deixando à linguagem verbal um papel complementar ou mesmo inferior. Olhando para essas imagens, que são um recorte das atividades previstas no curso (veremos isso mais adiante), questionamos se elas caracterizam uma real ruptura na percepção dos sujeitos do andamento regular de um encontro pedagógico.

A atuação do destinador nessas cenas em que os sujeitos ficam livres para "brincar" no Second Life, como um game, é de conferir importância a fazeres geralmente menosprezados no campo acadêmico, embora essas experiências lúdicas tenham também como finalidade uma visão crítica do método, como um objeto de pesquisa. A "diversão" é considerada, nesse curso, um valor nuclear no percurso do sujeito que deseja a conjunção com os objetos. Ela não só permite um encontro menos programado com esses objetos, como pode garanti-los, segundo esse ponto de vista.

A partir dessa ideia, as cenas a seguir devem ser vistas dentro de um projeto maior de experimentação, na medida em que essas atividades têm em vista uma reflexão de como tais recursos podem ser bem utilizados na educação. 
CASA, Vol.9 n.1, julho de 2011

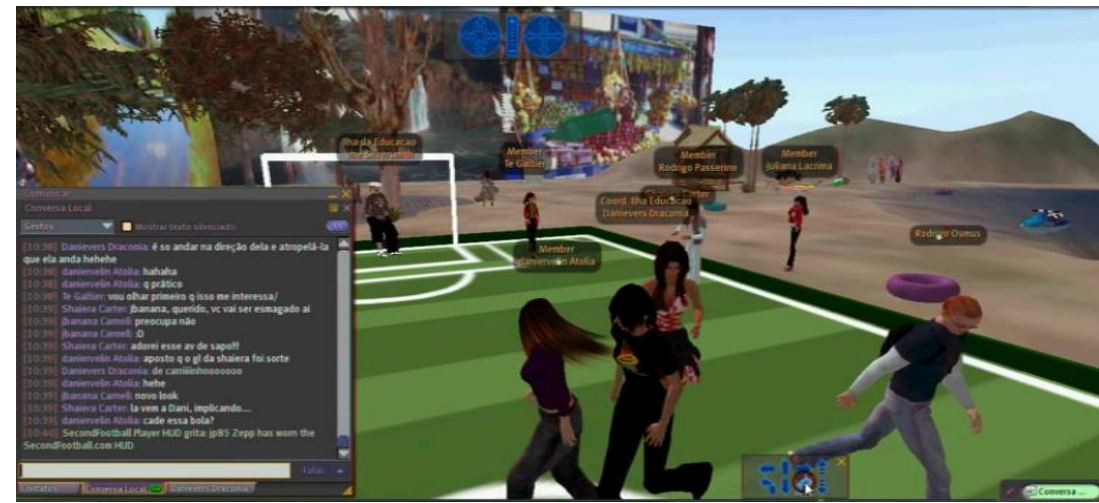

Figura 4: Cena de um jogo de futebol na área Brasil durante o curso "Games em educação no Second Life".

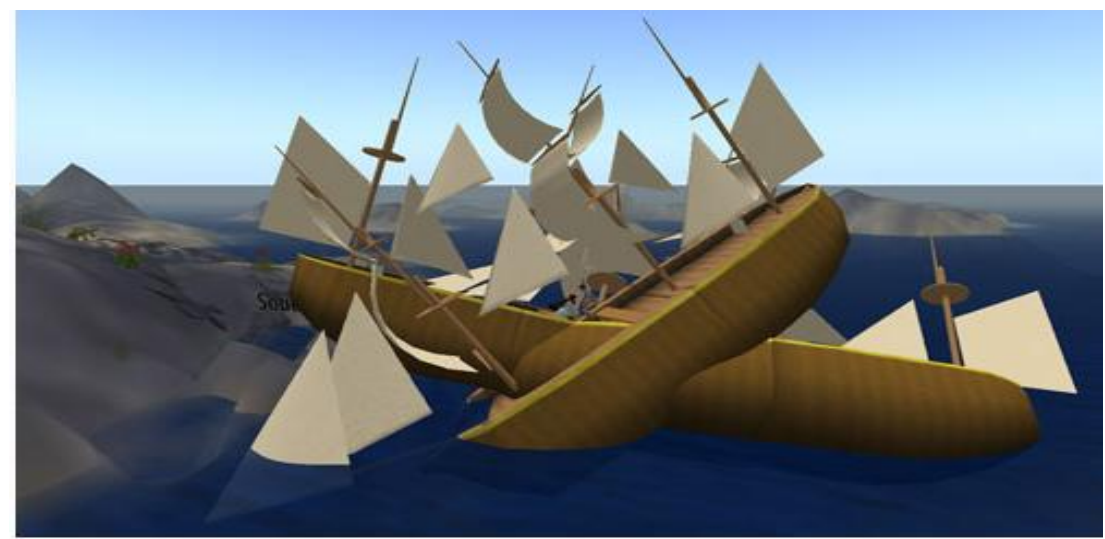

Figura 5: Cena de um choque entre barcos num passeio até as Ilhas Galápagos durante o mesmo curso

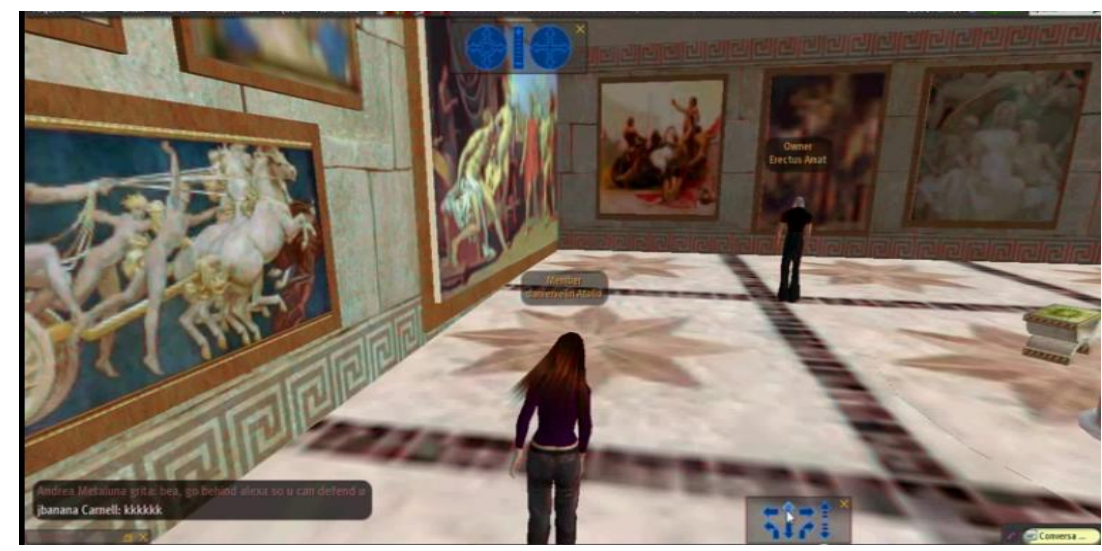

Figura 6: Cena de uma visita ao museu de Esparta durante o mesmo curso

Em geral, antes dessas atividades, o professor não estipulava o que devia ser feito, e era sempre frisado que todos ficassem livres para explorar os lugares para onde todos iam na segunda parte da aula, quando era cumprido o cronograma geral:

$(\ldots)$

[10:25] Professor: então, aqui no $\mathrm{sl}^{7}$ e no ava ${ }^{8}$, eu pretendo fazer 3 coisas por

\footnotetext{
${ }^{7}$ Second Life.

${ }^{8}$ Ambiente Virtual de Aprendizagem - usado para atividades assíncronas em fóruns, e-mails e outros.
}

Disponível em: http://seer.fclar.unesp.br/casa 
semana

[10:25] Professor: 1) dicutir 1 cap. do livro

[10:25] Professor: 2) conhecer algum lugar no sl em que estão sendo feitas pesquisas com games educacionais

(...)

[10:26] Professor: 3) completar o cap. do livro com mais material

(...) [interação no dia 31/03/2010]

Não ter um roteiro para essa parte lúdica do curso nos parece ser mais uma estratégia do destinador para propor um desvio do curso tradicional que a escola clássica sugere. Esse contrato, entretanto, nem sempre é aceito sem desconfiança, como mostra o comentário de um dos alunos na atividade da primeira cena (Figura 4) e respondido por outra aluna:

\section{(...) \\ [10:40] Aluno 6: sem querer ser chato, mas sendo, qual o objetivo dessa atividade??? \\ [10:40] Aluna 7: ai Aluno 3 eu ja tava indo cobrar o escanteio \\ [10:41] Aluna 8: Controle das ações no game \\ [10:41] Aluna 8: eu estou uma porcaria de ruim. \\ (...) [interação do dia 05/05/2010] [grifos nossos].}

O desafio, então, é provar que, embora não seja uma atividade "escolar", o objeto a ser conquistado continua sendo o valorizado no meio acadêmico. Há, nesse desafio, uma tentativa de rearticular e ressemantizar as partes de um processo cujo objetivo final é, assim, melhor assegurado, como mostram os trechos abaixo:

$(\ldots)$

[14:39] Professor: a empresa Lightspan

[14:39] Professor: em parceria com a Sony

[14:40] Professor: desenvolveu um projeto para crianças até a 8 série

[14:40] Professor: jogos jogados no playstation

[14:40] Professor: Centenas de escolas utilizaram os games

[14:40] Professor: para reforço curricular

(..)

[14:42] Professor: Click Health \& Games para a Saúde

[14:43] Professor: especializada em games educacionais para crianças com asma e diabete, e prevenção contra fumo

[14:43] Professor: lá atrás, em 1997

[14:43] Professor: crianças que jogaram o game Packy \& Marlon, p.ex.

[14:44] Professor: reduziram em 77\% em visitas de urgência a médicos e pronto-socorros

[14:44] Professor: comparando com crianças que não usaram os games

(...) (Interação do dia 12/05/2010).

No caso da instrução, cristaliza-se um fazer como fórmula do sucesso. Um passeio ou visita ao museu, por outro lado, poderia ativar o querer fazer, típico das diversões, e apagar o dever fazer, fortemente associado à educação. Outra proposta de inversão, aliada a essa, é quanto ao tempo e ao espaço. Espera-se uma limitação aos espaços habituais de um curso a distância (fórum, e-mail, chat), e o que ocorre é a diminuição da distância a lugares e tempos pouco acessíveis, como a visita a um museu na Grécia, a sensação de viajar como um 
personagem famoso da História, Darwin. Entre retomadas e avanços no processo de emparelhamento entre as práticas, "o sujeito se esforça, a exemplo de qualquer vivente, por tornar esse nicho [espaço tensivo] habitável, isto é, por ajustar e regular as tensões, organizando as morfologias que o condicionam" (FONTANILLE e ZILBERBERG, 2001, p. 128).

Identificamos, nesse ambiente, uma provável estratégia de suprir a "ausência" sentida no espaço digital, sintoma já observado por nós na análise de discursos de professores (PEREIRA, 2010, p. 228). Tal estratégia procura a proximidade da prática presencial, pela iconização, para diminuir os limites que separam os sujeitos e, assim, prepará-los para performances de efeito, ou seja, permitir um tal envolvimento dos sujeitos no percurso que o resultado só possa ser a convergência para um sincretismo entre enunciado e enunciação, quando enunciador, destinador e ator professor são uma só entidade presente aqui e agora. $\mathrm{O}$ mesmo para o enunciatário, destinatário/sujeito e ator aluno (sendo os papéis dos atores intercambiáveis).

O efeito resultante é uma presentificação que sensibiliza o sujeito e acena para a importância do afeto nesse processo - garantido pela devolução do "corpo", apagado na maioria das práticas digitais -, pois, como já observou Descartes: "se o objeto que se apresenta nada tiver em si para nos surpreender [...] consideramo-lo sem paixão" (apud FONTANILLE e ZILBERBERG, 2001, p. 128). Abaixo, um trecho mostra o impacto causado pelos recursos do ambiente digital:

Dessa forma, podemos estabelecer uma sequência de ações que se localizam paradigmaticamente ora na ordem do acontecimento, ora como exercício ou rotina, pelo crescendum e decrescendum de intensidade causados nas cenas. E temos, assim, para esse contexto, alguns elementos que sinalizam novas formas de vida - como regularidades no conjunto dos comportamentos (FONTANILLE, 2008) - no campo pedagógico que se constrói no ambiente digital, mas cuja base é a mesma observada em outros fenômenos. O que tentamos aqui é levantar algumas estratégias típicas dessa forma de vida.

\title{
Considerações finais
}

Parece-nos que uma abordagem pela semiótica tensiva, como pretendemos nesse texto, pode destacar mais nuances do objeto privilegiado e da própria teoria.

Cogitamos, por exemplo, na possibilidade de se falar em diferentes tipos de acontecimentos ou graus de acontecimento, pois é certo que temos no discurso pedagógico uma experiência distinta da que ocorre diante de uma obra de arte, por exemplo. Aqui, temos uma concentração máxima que exige operações de raciocínio, um papel, talvez, mais ativo do 
sujeito, embora possamos dizer que o objeto também desempenha um papel essencial e ativo sobre o sujeito. É preciso, entretanto, investigar melhor essa comparação, na medida em que o processo de recriação da obra de arte também pressupõe uma posição ativa.

Quanto ao objeto, a abordagem evidenciou que já há um enfoque para uma abertura de percursos em busca do conhecimento, que desperta no sujeito a sensibilidade para conduzir a aula num contínuo ajustamento, confiando na "sua intuição, na sua capacidade de sentir o momento, em ato, os prós e os contras de uma situação ou as disposições íntimas das pessoas com quem se lida [...] para tirar partido da ocasião". (LANDOWSKI, 2007, s/p) [tradução nossa]. Essa alteração no percurso não nega, entretanto, a existência e respeito à doxa nem o valor do planejamento da aula pelo professor como parte das estratégias necessárias.

Esses apontamentos nos direcionam a novas análises que possam, de alguma forma, colaborar para a consolidação dos conceitos teóricos empregados e para se alcançar noções mais abrangentes, mas adequadas a diferentes cenários educativos.

\section{Referências bibliográficas}

CORRÊA, J. (Org.). Estruturação de programas em EaD. Educação a distância. Porto Alegre: Artmed, 2007, p. 9-19.

DISCINI, N. Da percepção sensível. CASA - Cadernos de Semiótica Aplicada, vol.8, n. 2, p. 1-28, dezembro de 2010. Disponível em:

<http://seer.fclar.unesp.br/casa/article/viewFile/3330/3054>.

FONTANILLE, J. Stratégies doxiques. Explorations stratégiques. Actes sémiotiques. 25 mar. 1983, p. 34-46.

FONTANILLE, J. \& ZILBERBERG, C. Tensão e Significação. Trad. Ivã Carlos Lopes, Luiz Tatit e Waldir Beividas. São Paulo: Discurso Editorial: Humanitas/FFLCH/USP, 2001.

FONTANILLE, J. Práticas Semióticas: imanência e pertinência, eficiência e otimização. Trad. GESCOM-UNESP. In: DINIZ, M. L. V. P. \& PORTELA , J. C. (Orgs.). Práticas na mídia: textos práticas e estratégias. Bauru, SP: Edições FAAC, 2008, p. 17-76.

GREIMAS, A. J. Da imperfeição. Trad. Ana Cláudia Oliveira. São Paulo: Hackers Editores, 2002.

LANDOWSKI, E. Avant-propos: ajustements stratégiques. Nouveaux Actes Sémiotiques.

Disponível em: 〈http://revues.unilim.fr/nas/document.php?id=335>. N. 110, 2007.

LINDEMAN, M. Concept Maps, Instructional Design, and Constructivism. 2005.

Disponível em:

<http://www.ion.uillinois.edu/weblogs/lindeman/archives/2005/10/concept_maps_in.html>. Acesso em: 26 set. 2010.

MATTAR, J. Resenha sobre Instructional design, 2010. Disponível em: <http://blog.joaomattar.com/2010/02/08/instructional-design-2/>. Acesso em: 26 set. 2010.

MATTE, A. C. F. \& PEREIRA, D. R. M. Ignácio Assis Silva: a fantástica fábrica de conexões. CASA - Cadernos de Semiótica Aplicada. v.8, n.02, p. 1-13, dez. 2010. Disponível em: 〈http://seer.fclar.unesp.br/casa/article/viewFile/3317/3097>.

MERLEAU-PONTY, M. Fenomenologia da percepção. São Paulo: Martins Fontes, 1999. 
CASA, Vol.9 n.1, julho de 2011

PEREIRA, D. R. M. Atividades didáticas para ensino de português em ambiente digital: uma análise semiótica. 2010. 319 f. Dissertação de Mestrado apresentada à Universidade Federal de Minas Gerais (BH).

SMITH, P. L. \& RAGAN, T. J. Instructional design. 3 ed. Hiboken (NJ): John Wiley \& Sons, 2005.

TATIT, L. Semiótica à luz de Guimarães Rosa. São Paulo: Ateliê Editorial, 2010.

ZILBERBERG, C. Tocquevile et la valeur de la valeur. Alfa, n. 53, p. 365-389, 2009.

Disponível em: 〈http://seer.fclar.unesp.br/alfa/article/viewFile/2121/1739>. 